\title{
Hydrogen Effect on Zr-Nb-Mn Alloys for Nuclear Reactor Application
}

\author{
Thais de Brito Pintora * ${ }^{\circledR}$, Frederico Simkevicius Gabriel ${ }^{a}$, Rafaella Martins Ribeiro ${ }^{a}$ \\ ${ }^{a}$ Universidade Federal do Rio de Janeiro - UFRJ, Instituto Alberto Luiz Coimbra de Pós-Graduação \\ e Pesquisa de Engenharia - COPE, Programa de Engenharia Metalúrgica e de Materiais - PEMM, Rio \\ de Janeiro, RJ, Brasil
}

Received: February 22, 2019; Revised: December 1, 2019; Accepted: January 16, 2020

\begin{abstract}
$\mathrm{Zr}-\mathrm{Nb}-\mathrm{Mn}$ alloys were developed to investigate hydrogen diffusion and its effects among different manganese additions. Thermo-Calc ${ }^{\mathbb{B}}$ and TC-Prisma simulations were used to determine the studied chemical compositions and to estimate the volume fraction and the mean radius of precipitates. Three compositions were chosen to be melted and thermomechanically processed, resulting in an $\alpha$-Zr matrix with fine $\beta$-Nb precipitation. TDS results indicated that hydrogen diffusion coefficient was $10^{-12} \mathrm{~m}^{2} . \mathrm{s}^{-1}$ for all the analyzed compositions. The manganese addition increased the strength while ductility was maintained. Although optical microscopy revealed that the increase of manganese content resulted in less oriented hydrides, the reduction in ductility was similar for the three studied compositions. Results showed manganese as a promising addition element for zirconium alloys due to the increase of hydrogen solubility, the good relationship between strength and ductility and the morphology of the hydrides.
\end{abstract}

Keyword: hydride, zirconium alloys, nuclear materials.

\section{Introduction}

Zirconium alloys are widely used for the manufacture of nuclear components as fuel claddings, guide tubes and grid spacer materials due to their high mechanical properties, low neutron absorption capacity and good corrosion resistance when submitted to harsh environments with hydrogen ${ }^{1}$. To guarantee these singular properties in a Pressured Water Reactor (PWR) which operates under 160 atm at $593 \mathrm{~K}$, the chemical composition and the thermomechanical process must be controlled to obtain a partially or fully recrystallized microstructure to optimize critical properties ${ }^{2}$.

During PWR operation, radiolysis of the coolant water can generate hydrogen protons, which is absorbed by the alloy. This behavior results in hydride precipitation due to the low solubility of hydrogen in the $\alpha-Z r$ phase, reducing the life in service of reactor components. To minimize these unwanted effects, the control of the amount of hydride and its orientation is done through thermomechanical process design which induces crystallographic texture by aligning the $\alpha-\mathrm{Zr}$ grain parallel to the rods circumferential direction ${ }^{3}$.

Zirconium-based alloys with additions of niobium have been used in PWR reactors once this element improves corrosion resistance and delays the hydrogen absorption when fine and spherical $\beta$-phase precipitation occurs, which stabilizes the monoclinic zirconium oxide $\left(\mathrm{ZrO}_{2-\mathrm{x}}\right)^{1,4}$. Although there are well established commercial alloys such as Zircaloys, $\mathrm{Zr}-1 \mathrm{Nb}$ and $\mathrm{Zr}-1 \mathrm{Nb}-1 \mathrm{Sn}-0.1 \mathrm{Fe}$, the development of new materials is still interesting to guarantee fuel claddings integrity and extend the life span of these components. For this purpose, the computational simulation has increasingly been used to optimize experimental tests. The CALPHAD (CALculation of Phase Diagrams) base models can predict phase equilibrium relationship and phase diagrams for complex multi-component systems ${ }^{5}$.

*e-mail: pintor.thais@gmail.com
Studies $^{4,6,7}$ have been proposing the addition of new alloying elements to delay hydrogen embrittlement to increase hydrogen solubility, stabilize the oxide layer or optimize the manufacturing process, aiming to understand the influence of microstructure on hydrogen absorption kinetics. In recent years, the addition of Mn in alloys which presents an hcpbcc phase transition - as $\mathrm{Ti}$ and $\mathrm{Mg}$, has been evaluated once this element exhibits potential to produce a low-cost material, with a good combination of strength and ductility and good conformability ${ }^{8}$.

Ribeiro et al. ${ }^{6}$, when evaluating the effect of the addition of alloying elements on a $\mathrm{Zr}-\mathrm{Nb}$ based alloy, indicated that manganese can delay the absorption of hydrogen even in more susceptible microstructures, such as cold rolled materials. Therefore, this work aims to evaluate the manganese influence on hydrogen diffusion and its effect on mechanical properties in a $\mathrm{Zr}-\mathrm{Nb}$ alloy by using CALPHAD simulation to sort chemical compositions to be melted and thermomechanically processed by rolling and annealing. Additionally, $\beta-\mathrm{Nb}$ precipitation was simulated and confirmed by Transmission Electron Microscopy (TEM), hydrogen coefficient parameters were determined by Thermal Desorption Spectroscopy (TDS) and hydride embrittlement was evaluated by tensile test and hydride morphology and orientation observation by optical microscopy (OM).

\section{Experimental details}

Thermo-Calc ${ }^{\circledR}$ software was used to determine promising chemical compositions through analyzing isoplethal graphics, with the PURE5 base (5.0.4.75 version), and cooling curves, using the TBIC base ( $2015 \alpha$ version), considering the stoichiometry $99 \mathrm{Zr}-\mathrm{xNb}-(1-\mathrm{x}) \mathrm{Mn}$. Three compositions were selected to be melted in an arc melting furnace Bühler AM Vario-400 under an argon atmosphere at 200 mbar. Specimens were turned over and remelted four times to achieve chemical 
homogeneity, resulting in ingots with $60 \mathrm{~g}$ measuring 100 $\mathrm{mm}$ length, $15 \mathrm{~mm}$ width and $10 \mathrm{~mm}$ thickness.

The ingots were soaked at $923 \mathrm{~K}$ for $20 \mathrm{~min}$ and subsequently hot rolled in the longitudinal direction, submitting them to $40 \%$ of reduction. The specimens were then soaked at 1223 $\mathrm{K}$ for $12 \mathrm{~min}$ and hot rolled in the transversal direction, resulting in $52 \%$ of reduction. The plates were $\beta$-solution treated at $1273 \mathrm{~K}$ for $10 \mathrm{~min}$ followed by quenching into the water. Then, pre-heated at $1123 \mathrm{~K}$ for 15 minutes and hot rolled in a longitudinal direction until reaching $64 \%$ of reduction. The annealing processes preceding each rolling step were performed by the software Deform ${ }^{\mathrm{TM}}-3 \mathrm{D}$.

The sheets were cold rolled through slight deformation passes to obtain about $0.75 \mathrm{~mm}$ thickness. Finally, all the sheets were annealed in a Carbolite vacuum furnace at $923 \mathrm{~K}$ for $2 \mathrm{~h}$ and cooled into the furnace. To predict the precipitation volume fraction and mean radius TC-Prisma package with the commercial TCFE8 and MOBFE3 database was used considering the annealing condition.

TEM images for heat treated alloys were obtained with a Jeol JEM-2010 microscope at $200 \mathrm{kV}$, using simultaneously light field for the matrix and the dark field for the precipitates. The samples were cut, SiC grinded with 1200 and 2500 sandpapers and electropolished in dual jet Struers Tenupol 5 device with a solution of 9 vol. $\% \mathrm{HClO}_{4}$ and 91 vol.\% $\mathrm{C}_{2} \mathrm{H}_{4} \mathrm{O}_{2}$ under $26 \mathrm{~V}$ at $292 \mathrm{~K}$.

To evaluate hydrogen diffusion on the alloys, gas hydrogenation was performed at $593 \mathrm{~K}$ under 10 bar hydrogen gas atmospheres for $48 \mathrm{~h}$. Sample preparation consisted of SiC grinding with 220, 400, 600 and 1200 sandpapers. Thermal Desorption Spectroscopy (TDS) technique with quadrupole mass spectrometer was performed at $573 \mathrm{~K}$ for 7 $\mathrm{h}$ to determine the hydrogen diffusion coefficient. Based on Kirchheim ${ }^{9}$ studies, the inflection point $\left(\mathrm{t}_{\mathrm{i}}\right)$ of the integration of the TDS curves and the thickness of the sample (x) enabled to determine the value of diffusion coefficient, by Equation 1:

$$
D=\ln 16 . x^{2} / 3 \pi^{2} \cdot t_{i}
$$

X-ray diffraction analyses were conducted at room temperature with a Bruker D8 Discover diffractometer using $\mathrm{Cu}-\mathrm{K}_{\alpha}$ radiation to determine sample phase structures before and after hydrogen absorption.

Tensile tests of non-hydrided and hydrided specimens were performed at room temperature using an EMIC $100 \mathrm{kN}$ machine at a stain rate of $10^{-5} \mathrm{~s}^{-1}$, according to ASTM E8$15^{10}$. Fracture surfaces of the specimens were observed with a JEOL JSM 6460 scanning electron microscope under 20 $\mathrm{kV}$. To saturate the samples by hydrogen, an electrochemical hydrogenation at $0.03 \mathrm{~A}$ for $72 \mathrm{~h}$ in the $0.01 \mathrm{~mol} / \mathrm{L} \mathrm{LiOH}$ was done before the tensile test, just in the test area.

Hydride distribution and orientation through transversal direction were observed by optical microscopy using an Olympus BX60M. Samples were electrochemically hydrogenated with the same conditions described previously for tensile tests, prepared by $\mathrm{SiC}$ grinding with 220, 400, 600 and 1200 sandpapers and polishing with Struers cloths OP- CHEM $200 \mathrm{~mm}$ using a 10\% oxalic acid solution.

\section{Results and Discussion}

To determine the influence of manganese addition on the expense of niobium addition, simulation of $99 \mathrm{Zr}-\mathrm{xNb}-$ (1-x)Mn was performed, Figure 1. It is possible to observe that the solidification occurs at $2130 \mathrm{~K}$, forming a stable bcc region, followed by an allotropic transformation from $\beta$-phase (bcc) to $\alpha$-phase (hcp), with a two-phase region (bcc + hcp) between $4 \%$ and $27 \%$ of niobium started from $1123 \mathrm{~K}$. This phase transition is characteristic of zirconium element and is the most important transition for zirconium alloys, once bcc structure has more slip planes than hcp, resulting in a better conformability of the zirconium alloy ${ }^{1}$. Literature $^{1}$ reported transformation temperature of $1143 \mathrm{~K}$ however, for $\mathrm{Zr}-\mathrm{Nb}-\mathrm{Mn}$, the transformation occurs at lower temperature $(1123 \mathrm{~K})$, suggesting that manganese, as niobium, is a strong $\beta$-stabilizer once it has a bcc structure forming a larger bec stability region.

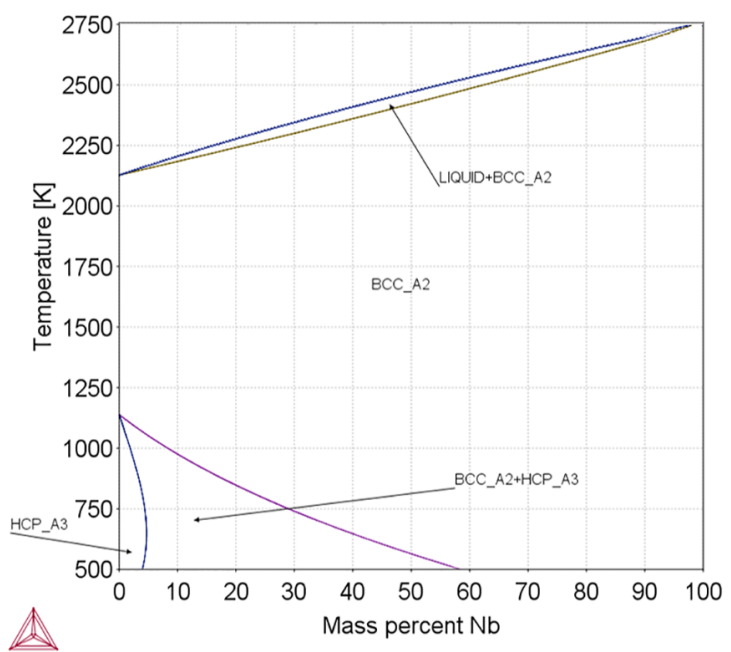

Figure 1. Isoplethal of $99 \mathrm{Zr}-\mathrm{xNb}-(1-\mathrm{x}) \mathrm{Mn}$, replacing $\mathrm{Nb}$ with $\mathrm{Mn}$.

Ribeiro et al. ${ }^{6}$, when studying the influence of manganese addition on $\mathrm{Zr}-0.8 \mathrm{Nb}-0.2 \mathrm{Mn}$, obtained a fully recrystallized microstructure consisted of spherical and elongated $\beta-\mathrm{Nb}$ precipitates dispersed in an $\alpha-\mathrm{Zr}$ matrix. No segregation of manganese was observed by EDX analysis indicating that this element was distributed throughout the material. To optimize the desired properties for nuclear applications, the amount of manganese must be controlled to guarantee the formation of a fine and dispersed $\beta-\mathrm{Nb}$ precipitation in an $\alpha-\mathrm{Zr}$ matrix. For these reasons, the compositions selected to be developed in this study were: $\mathrm{Zr}-0.9 \mathrm{Nb}-0.1 \mathrm{Mn}, \mathrm{Zr}-$ $0.8 \mathrm{Nb}-0.2 \mathrm{Mn}$ and $\mathrm{Zr}-0.6 \mathrm{Nb}-0.4 \mathrm{Mn}$.

Considering that the thermomechanical process guarantees the desired microstructure, it is substantial to 
know the temperature for each phase transformation to define the best process conditions. For this purpose, cooling curves were simulated for each proposed composition, as shown in Figure 2. It can be seen that the solidification process started at $2118 \mathrm{~K}$, forming a bcc structure, and finished around $1120 \mathrm{~K}$ for all compositions. The bcc phase remained stable until $1125 \mathrm{~K}$ for $\mathrm{Zr}-0.6 \mathrm{Nb}-0.4 \mathrm{Mn}$, $1119 \mathrm{~K}$ for both $\mathrm{Zr}-0.8 \mathrm{Nb}-0.2 \mathrm{Mn}$ and $\mathrm{Zr}-0.9 \mathrm{Nb}-0.1 \mathrm{Mn}$, when the phase transition from bec to hcp started. It was possible to observe that, even being a $\beta$-phase stabilizer, manganese is less effective than niobium once the increase of manganese and the consequent reduction of niobium content results in an increase of the allotropic transformation temperature. After that, there is a twophase region $(\mathrm{hcp}+\mathrm{bcc}$ ) between $1125 \mathrm{~K}$ and $893 \mathrm{~K}$ and for lower temperatures, most of the bcc phase was transformed in the hop phase.

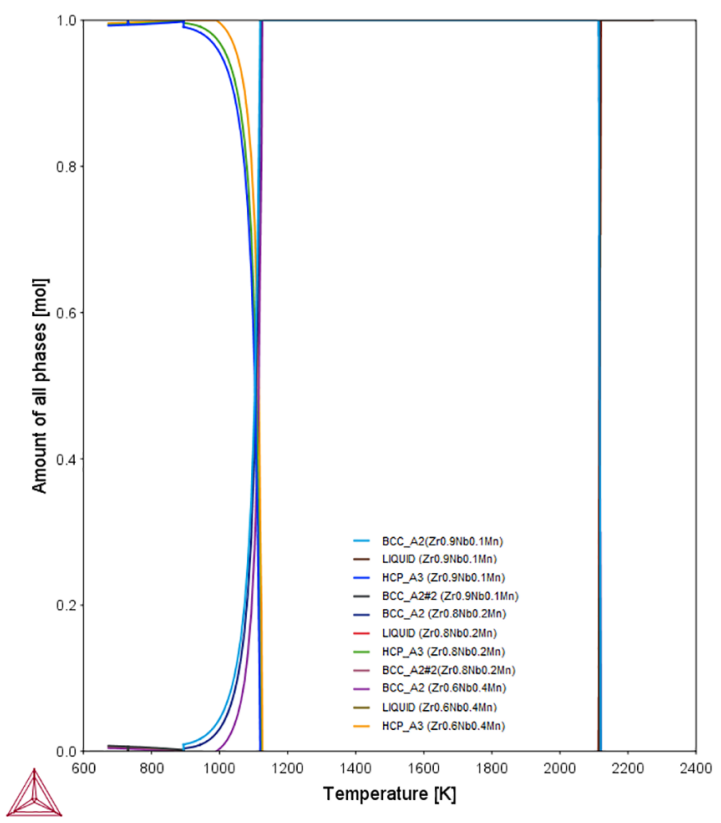

Figure 2. Simulation of cooling curves of $\mathrm{Zr}-0.9 \mathrm{Nb}-0.1 \mathrm{Mn}$, $\mathrm{Zr}-0.8 \mathrm{Nb}-0.2 \mathrm{Mn}$ and $\mathrm{Zr}-0.6 \mathrm{Nb}-0.4 \mathrm{Mn}$.

The analysis of the thermomechanical process can be divided into three main steps: hot rolling, cold rolling and annealing. Regarding the hot rolled process, it was possible to obtain plates with no cracks or considerable surface oxidation. The cold rolled process produced small cracks just on plates edges. $\mathrm{Zr}-0.9 \mathrm{Nb}-0.1 \mathrm{Mn}$ required one more pass, compared with the other compositions, to reach the same total reduction planned for hot and cold rolled steps. This results are in accordance with Ribeiro et al. ${ }^{6}$, which processed a Zr- $0.8 \mathrm{Nb}-0.2 \mathrm{Mn}$ alloy by cold rolling and obtained a plate with no significant cracks and also can be comparable to Oliveira et al. ${ }^{11}$ that obtained the same surface results when processing $\mathrm{Zr}-1 \mathrm{Nb}$ and $\mathrm{Zr}-1 \mathrm{Nb}-1 \mathrm{Sn}-0.1 \mathrm{Fe}$ alloy through a similar deformation process.
The time and temperature of the heat treatment were defined based on Tian et al. ${ }^{2}$, which indicated that a fully recrystallized microstructure could be achieved at $873 \mathrm{~K}$ after 84 minutes in a $30 \%$ deformed $\mathrm{Zr}-1 \mathrm{Nb}$ alloy. Additionally, Oliveira et al. ${ }^{11}$ obtained a partially recrystallized microstructure with fine precipitation by $2 \mathrm{~h}$ at $873 \mathrm{~K}$ annealing through a thermomechanical process similar to this work.

TC-Prisma package was used to determine the relationship between the volume fraction and mean radius of $\beta-\mathrm{Nb}$ precipitation, Table 1 . The simulation predicted that, for heat treatment at $923 \mathrm{~K}$ for $2 \mathrm{~h}$, the mean radius of $\beta-\mathrm{Nb}$ precipitates decreases while the volume fraction of the precipitates increases with manganese. These results indicated that manganese could change the precipitation kinetics. The same behavior was observed in $\mathrm{Nb}$ steels containing high levels of $\mathrm{Mn}^{12}$.

Table 1. Simulation of volume fraction and mean radius by TC-Prisma.

\begin{tabular}{lcc}
\hline Alloy & Volume fraction & Radius (nm) \\
\hline Zr-0.9Nb-0.1Mn & 1.98 & 1.24 \\
Zr-0.8Nb-0.2Mn & 2.71 & 1.17 \\
Zr-0.6Nb-0.4Mn & 4.08 & 1.07 \\
\hline
\end{tabular}

Figure 3 shows the diffraction pattern of $\mathrm{Zr}-0.9 \mathrm{Nb}$ $0.1 \mathrm{Mn}, \mathrm{Zr}-0.8 \mathrm{Nb}-0.2 \mathrm{Mn}$ and $\mathrm{Zr}-0.6 \mathrm{Nb}-0.4 \mathrm{Mn}$ under different processing conditions. The XRD analyses indicate that all alloys have an $\alpha$ - $\mathrm{Zr}$ matrix. The $\beta$-phase precipitates could not be observed by XRD due to their low volume fraction ${ }^{6,11}$.

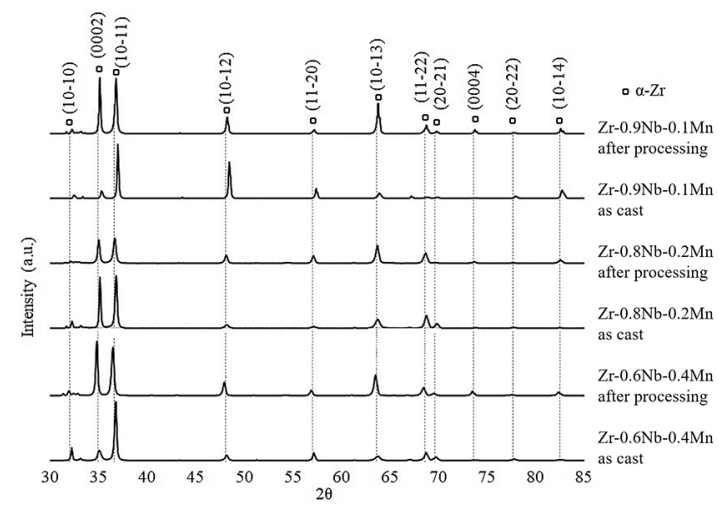

Figure 3. XRD pattern of the $\mathrm{Zr}-0.9 \mathrm{Nb}-0.1 \mathrm{Mn}, \mathrm{Zr}-0.8 \mathrm{Nb}-0.2 \mathrm{Mn}$ and $\mathrm{Zr}-0.6 \mathrm{Nb}-0.4 \mathrm{Mn}$ alloys as cast and after the thermomechanical process.

TEM micrographs for the $\mathrm{Zr}-0.6 \mathrm{Nb}-0.4 \mathrm{Mn}$ alloy after heat treatment at $923 \mathrm{~K}$ for $2 \mathrm{~h}$, Figure 4, show the presence of spherical and well-dispersed precipitates, with a mean radius of $1.8 \mathrm{~nm}$ in the zirconium matrix, confirming TC-Prisma simulation results, presented in Table 1. The development of microstructures containing nanoparticles $\beta-\mathrm{Nb}$, can enhance critical properties as corrosion and creep resistance, as well as influence the post-irradiation mechanical behavior of the material ${ }^{1,13}$. 


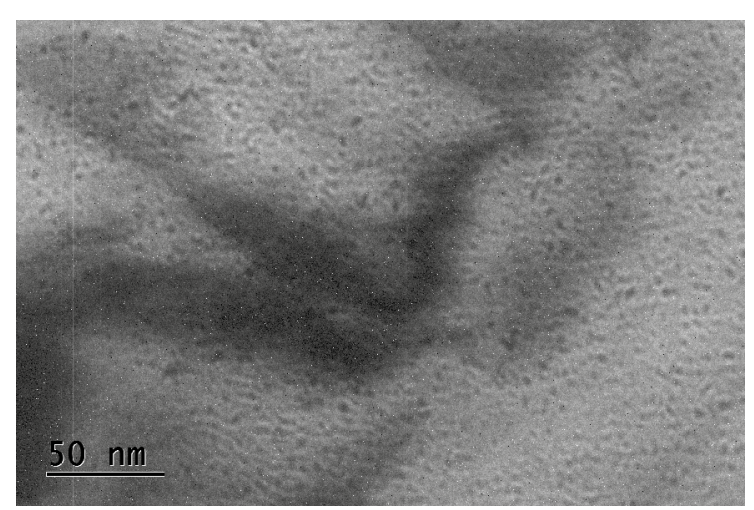

Figure 4. $\mathrm{Zr}-0.6 \mathrm{Nb}-0.4 \mathrm{Mn}$ after heat treatment showing an $\alpha-\mathrm{Zr}$ matrix and spherical dispersed $\beta$-phase precipitates.

The effect of the microstructure on hydrogen diffusion, $\mathrm{Zr}-0.9 \mathrm{Nb}-0.1 \mathrm{Mn}$ alloy was analyzed by isothermal TDS under the cold rolled and annealed conditions, Figure 5. Both conditions presented only one desorption peak although the peak intensity of the cold rolled sample was higher than the annealed one, once that has more hydrogen traps, as higher dislocation density and irregularities than that of the specimen after heat treatment. Traps with low binding energy, such as dislocations, have higher release rate, accounting for the high peak for cold rolled sample ${ }^{14}$. The proton of hydrogen is not uniformly distributed in the alloy microstructure so during desorption it can move randomly through one site to another in the crystalline structure and can also be re-trapped. In annealed microstructures of zirconium alloys, there are reversible traps - such as precipitate-matrix interfaces, grain boundaries, dislocations, vacancies - and irreversible traps, like hydrides or secondary phases ${ }^{14}$. For a $\mathrm{Zr}-1 \mathrm{Nb}$ alloy, these traps have different hydrogen site energies, where irreversible traps present the highest energy $(\mathrm{E}=24.5 \mathrm{~kJ} / \mathrm{mol})$ followed by $\beta$-precipitate interface $(\mathrm{E}=18.2 \mathrm{~kJ} / \mathrm{mol})^{15}$.

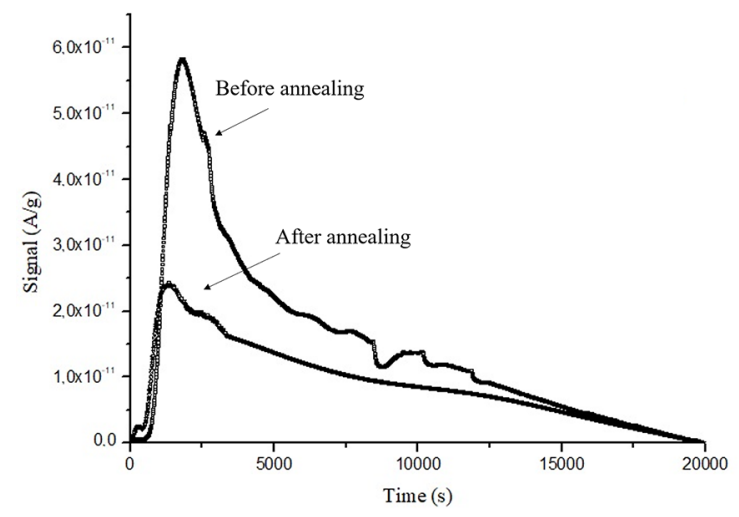

Figure 5. TDS of Zr-0.9Nb-0.1Mn alloy before and after annealing.

The isothermal TDS spectrum of the hydrogenated annealed alloys presented one peak as indicated in Figure 6. This suggests the existence of one reaction during hydrogen desorption at $300^{\circ} \mathrm{C}$ independent of the analyzed composition.
However, the peak intensity rose with the increase of manganese content, which could be associated with the higher precipitates volume fraction predicted by TC-Prisma simulation, acting as a hydrogen trapping. As the desorption temperature applied in this test was lower than that required to hydride decomposition and desorption ${ }^{16}$, the reaction observed can be attributed to energy sites that have lower potential energy levels for hydrogen trapping, as grain boundaries, interfaces and dislocations $\mathbf{s}^{15}$.

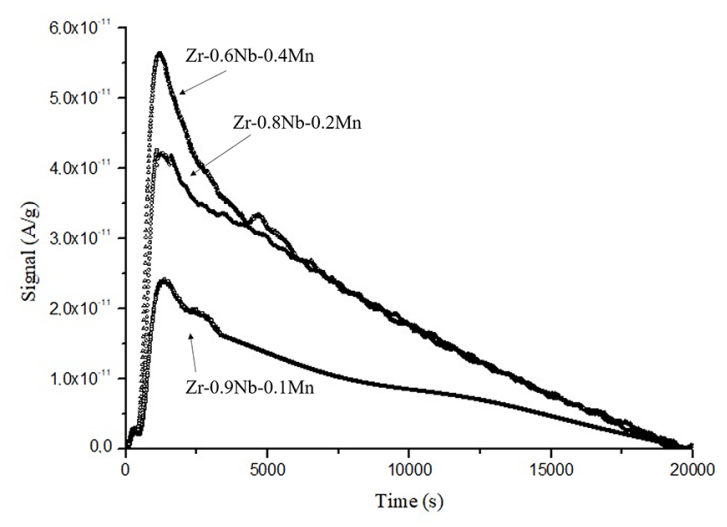

Figure 6. TDS spectra of the hydrogenated $\mathrm{Zr}-0.9 \mathrm{Nb}-0.1 \mathrm{Mn}$, $\mathrm{Zr}-0.8 \mathrm{Nb}-0.2 \mathrm{Mn}$ and $\mathrm{Zr}-0.6 \mathrm{Nb}-0.4 \mathrm{Mn}$ alloys under annealed condition.

Although hydrogen gas permeation technique is currently used to determine the coefficient diffusion of materials; however, for some zirconium alloys, as $\mathrm{Zr}-1 \mathrm{Nb}$, hydrogen diffusivity is very low and atoms do not permeate through the sample due to the formation of a hydride front ${ }^{15,17}$, preventing hydrogen diffusion and the flux data acquisition. As an alternative, Kirchheim ${ }^{9}$ proposed the determination of hydrogen diffusion flux through the integration of TDS peak, Equation 2. Therefore, Shrivastava et al. ${ }^{17}$ used extractionquadrupole mass spectrometry and constant temperatures to estimate the hydrogen diffusivity parameters for a $\mathrm{Zr}-2.5 \mathrm{Nb}$ alloy. Both studies obtained the diffusion coefficients using Equation 1. This solution was applied for the three analyzed compositions and the results were presented in Table 2.

$$
J(l / 2, t)=\frac{4 C_{f i} D_{f}}{l} \sum_{n=0}^{\infty} \exp \left[-\frac{\pi^{2}(2 n+1)^{2} F(t)}{l^{2}}\right]
$$

Table 2. Hydrogen diffusion parameters obtained by TDS tests.

\begin{tabular}{lcc}
\hline Alloy & Dapp $\left(\mathrm{m}^{2} / \mathrm{s}\right)$ & Solubility $\left(\mathrm{m}^{3}\right)$ \\
\hline Zr-0.9Nb-0.1Mn & $2.6 \mathrm{E}^{-12} \pm 0.6$ & 26.7 \\
Zr-0.8Nb-0.2Mn & $3.8 \mathrm{E}^{-12} \pm 0.8$ & 41.3 \\
Zr-0.6Nb-0.4Mn & $2.8 \mathrm{E}^{-12} \pm 0.7$ & 52.3 \\
\hline
\end{tabular}

Considering that the calculated diffusion coefficient is different from the real one, once the samples have different hydrogen traps and irregularities in the microstructure, this work presents the apparent diffusion coefficient $\left(\mathrm{D}_{\text {app }}\right)^{18}$. 
By the values presented in Table 2, the apparent diffusion coefficient from the proposed alloys was similar, about $3 \times 10^{-12} \mathrm{~m}^{2} / \mathrm{s}$. Despite the fact that alloys have different compositions, they basically consist of an $\alpha-\mathrm{Zr}$ matrix with small microstructure differences ${ }^{19}$ which can explain the similar diffusion coefficients. Additionally, there are many mechanisms delaying the hydrogen diffusion, such as the free niobium and manganese atoms which delay the hydrogen diffusion ${ }^{3}$ and the formation of hydrides ${ }^{15}$. Moreover, in this work the material was hydrogenated and then the test was performed, so an unexpected behavior of hydrogen re-trapping in available sites could also delay the diffusion.

These values are in agreement with hydrogen gas permeation technique results ${ }^{15,20}$ and with extractionquadrupole mass spectrometry result ${ }^{17}$. As expected, the alloy with higher manganese content ( $\mathrm{Zr}-0.6 \mathrm{Nb}-0.4 \mathrm{Mn})$, which has the highest precipitate volume fraction, presented the highest solubility, once it has more interfaces that act as hydrogen traps, increasing the hydrogen solubility. The alloy with less manganese content had less precipitate volume fraction and, consequently, the lowest solubility since this composition may have fewer interfaces and hydrogen can permeate more easily through the microstructure. Analogously, $\mathrm{Zr}-0.8 \mathrm{Nb}-0.2 \mathrm{Mn}$ alloy presented an intermediary solubility.

Hydride distribution and orientation in the transverse section of the specimens were observed by OM, Figure 7. In $\mathrm{Zr}-0.9 \mathrm{Nb}-0.1 \mathrm{Mn}$ alloy, hydrides were elongated and oriented in the rolling direction. With the increase of the manganese content and reduction of the niobium content, the hydrides formed were less oriented and shorter, as can be observed in Figure 7 (b) and (c) for the $\mathrm{Zr}-0.8 \mathrm{Nb}-0.2 \mathrm{Mn}$ and $\mathrm{Zr}-0.6 \mathrm{Nb}-0.4 \mathrm{Mn}$, respectively. As hydride orientation is strongly dependent on crystallographic texture developed in the thermomechanical process ${ }^{2}$, the existence of oriented hydrides indicates that microstructure is partially recrystallized. The same behavior was observed in literature for other zirconium alloys ${ }^{15}$.

The results suggest that the increase of the manganese content, which remains in solid solution, associated with the reduction of the niobium content, affects the microstructure, inducing a texture-relief, as it was seen in molybdenum addition in $\mathrm{Zr}-\mathrm{Nb}$ and $\mathrm{Zr}-\mathrm{Nb}$-Sn, which decreased the normal basal texture after heat treatment ${ }^{21}$.

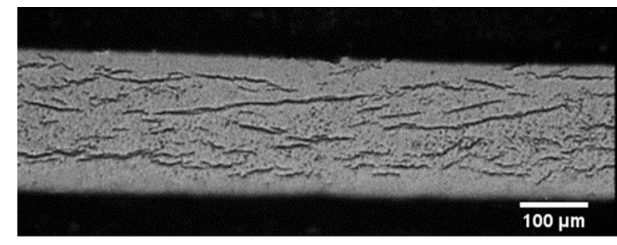

(a)

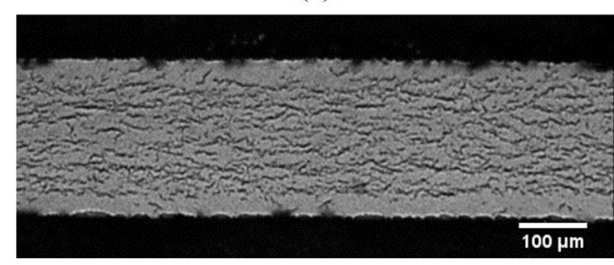

(b)

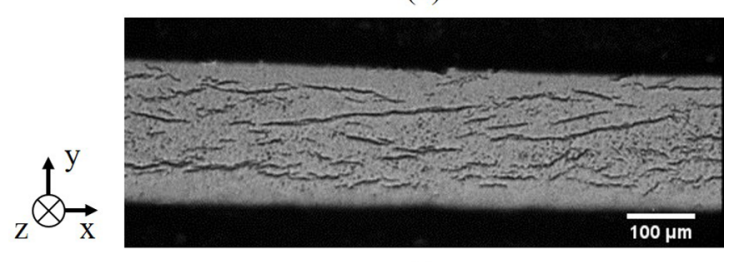

$\otimes$ Rolling direction

(c)

Figure 7. Transversal section of plates after electrolytic hydrogenation for $72 \mathrm{~h}$ showing hydride distribution and orientation for (a) $\mathrm{Zr}$ $0.9 \mathrm{Nb}-0.1 \mathrm{Mn}$, (b) Zr-0.8Nb-0.2Mn and (c) Zr-0.6Nb-0.4Mn.

The tensile properties of $\mathrm{Zr}-0.9 \mathrm{Nb}-0.1 \mathrm{Mn}, \mathrm{Zr}-0.8 \mathrm{Nb}-$ $0.2 \mathrm{Mn}$ and $\mathrm{Zr}-0.6 \mathrm{Nb}-0.4 \mathrm{Mn}$ before and after hydrogenation are presented in Table 3. The results of the annealed samples showed that the ultimate tensile strength increased with manganese content while yield strength and elongation remained statistically equal. The results indicate that manganese addition increased the strength, which could be mainly associated with the solid solution hardening mechanism and did not adversely affect ductility corroborating with the literature ${ }^{6}$, which indicates that manganese increases the conformability and maintains a good relationship between strength and ductility. Yang et al..$^{22}$ studied the hardening mechanisms of the niobium addition and identified that, for contents lower than $0.5 \mathrm{wt} . \%$, hardening occurred mainly by solid solution whereas the precipitation hardening becomes expressive for contents greater than or equal to $1 \mathrm{wt} . \%$.

For the hydrogenated samples, the reduction of all the mechanical properties, especially the ductility, was observed

Table 3.Tensile test results for $\mathrm{Zr}-0.9 \mathrm{Nb}-0.1 \mathrm{Mn}, \mathrm{Zr}-0.8 \mathrm{Nb}-0.2 \mathrm{Mn}$ and $\mathrm{Zr}-0.6 \mathrm{Nb}-0.4 \mathrm{Mn}$ before and after hydrogenation.

\begin{tabular}{lccccc}
\hline Alloy & $\begin{array}{c}\text { Yield Strength } \\
{[\mathbf{M P a}]}\end{array}$ & $\begin{array}{c}\text { Yield Strength } \\
\mathbf{( 0 . 2} \text { \% offset) [MPa] }\end{array}$ & $\begin{array}{c}\text { Tensile Strength } \\
{[\mathbf{M P a}]}\end{array}$ & Elongation [\%] & Condition \\
\hline \multirow{2}{*}{$\mathrm{Zr}-0.9 \mathrm{Nb}-0.1 \mathrm{Mn}$} & $261 \pm 11$ & $281 \pm 14$ & $438 \pm 16$ & $19 \pm 7$ & non-hydrogenated \\
& $248 \pm 23$ & $268 \pm 15$ & $432 \pm 19$ & $15 \pm 4$ & hydrogenated \\
$\mathrm{Zr}-0.8 \mathrm{Nb}-0.2 \mathrm{Mn}$ & $258 \pm 14$ & $280 \pm 23$ & $445 \pm 23$ & $19 \pm 8$ & non-hydrogenated \\
& $242 \pm 10$ & $266 \pm 11$ & $414 \pm 17$ & $16 \pm 1$ & hydrogenated \\
$\mathrm{Zr}-0.6 \mathrm{Nb}-0.4 \mathrm{Mn}$ & $261 \pm 5$ & $287 \pm 5$ & $469 \pm 6$ & $18 \pm 5$ & non-hydrogenated \\
& $251 \pm 7$ & $268 \pm 1$ & $426 \pm 12$ & $14 \pm 4$ & hydrogenated \\
\hline
\end{tabular}


independently of the chemical composition due to the presence of hydrides formed during hydrogen absorption. It is important to highlight that the increase of manganese content resulted in an increase in the ultimate tensile strength. However, after hydrogenation, the reduction in ductility was similar for the three studied compositions, around $20 \%$. TDS results showed that solubility increases with manganese content and Ribeiro et al. ${ }^{6}$ observed a delay in hydrogen absorption in different microstructures of $\mathrm{Zr}-0.8 \mathrm{Nb}-0.2 \mathrm{Mn}$ alloy, which could explain this behavior. Further absorption kinetic tests and texture analysis must be done to complement this observation and elucidate the mechanism of Mn addition in hydrogen absorption.

\section{Non-hydrogenated}

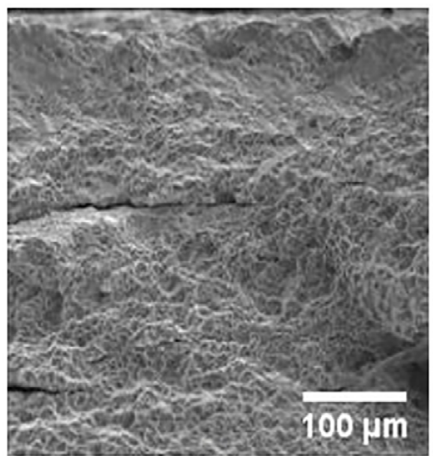

(a)

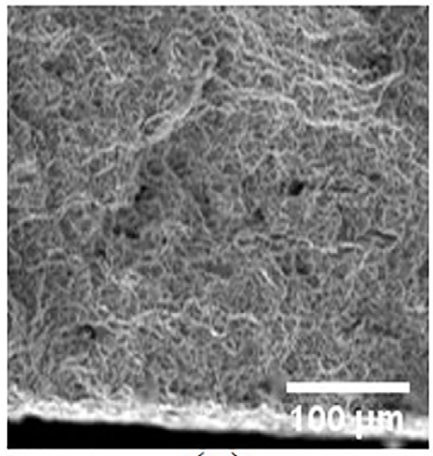

(c)

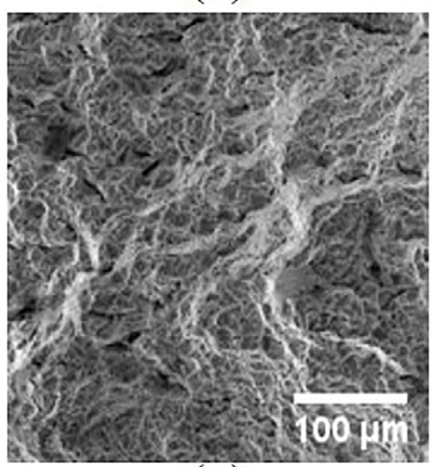

(e)
SEM fractography of all testing conditions shows a ductile fracture aspect by microvoid coalescence, Figure 8 . Non-hydrides specimens presented secondary cracks, which may explain the low values of yield strength and resistance observed for alloys with higher niobium content. The presence of secondary cracks in commercial zirconium alloys under similar processing conditions was observed by Oliveira et al. ${ }^{11}$. $\mathrm{Zr}-0.9 \mathrm{Nb}-0.1 \mathrm{Mn}$ presented long cracks, around $250 \mu \mathrm{m}$, perpendicular to the loading direction, while the compositions with higher manganese content had smaller, 10-20 $\mu \mathrm{m}$, and less oriented cracks, Figure 8 (a), (b) and (c).

\section{Hydrogenated}

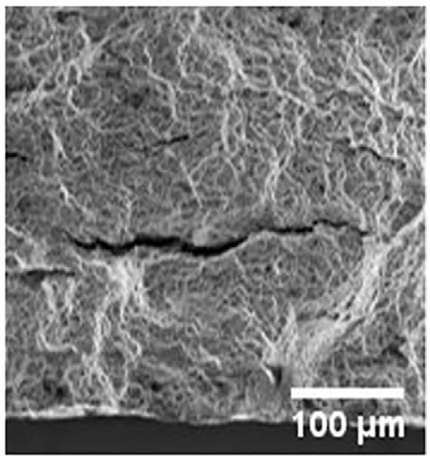

(b)

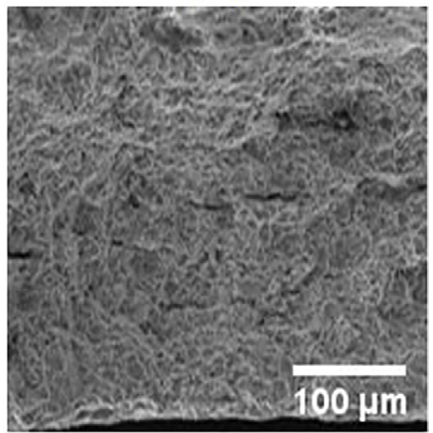

(d)

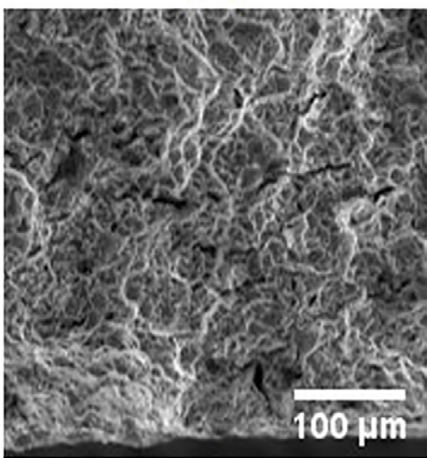

(f)

Figure 8. Fractography after tensile test for the proposed alloys under non-hydrogenated and hydrogenated conditions. a) $\mathrm{Zr}-0.9 \mathrm{Nb}-0.1 \mathrm{Mn}$ without $\mathrm{H}$; b) $\mathrm{Zr}-0.9 \mathrm{Nb}-0.1 \mathrm{Mn}$ with $\mathrm{H}$; c) $\mathrm{Zr}-0.8 \mathrm{Nb}-0.2 \mathrm{Mn}$ without $\mathrm{H}$; d) $\mathrm{Zr}-0.8 \mathrm{Nb}-0.2 \mathrm{Mn}$ with $\mathrm{H}$; e) $\mathrm{Zr}-0.6 \mathrm{Nb}-0.4 \mathrm{Mn}$ without $\mathrm{H}$ and f) $\mathrm{Zr}-0.6 \mathrm{Nb}-0.4 \mathrm{Mn}$ with $\mathrm{H}$. 
For the hydrogenated alloys, ductile fracture features were prevalently accompanied by the presence of secondary cracks with a quasi-cleavage aspect, typical of hydride embrittlement. As hydrides are a brittle phase, cracks will propagate through hydride/matrix interface, inducing a localized resistance loss and the formation of brittle regions, while matrix fracture remains ductile. As a result, a significant loss of strength and ductility was observed. The same behavior was identified by Vazquez et al. ${ }^{13}$ when studying the effect of hydrogen on $\mathrm{Zr}-1 \mathrm{Nb}$ and $\mathrm{Zr}-2.5 \mathrm{Nb}$ alloys. The size of the secondary cracks increased in relation to the non-hydrogenated condition, $500 \mu \mathrm{m}$ for the $\mathrm{Zr}-0.9 \mathrm{Nb}-0.1 \mathrm{Mn}$ alloy and $20 \mu \mathrm{m}$ for the $\mathrm{Zr}-0.6 \mathrm{Nb}-0.4 \mathrm{Mn}$ alloy.

Comparing the performance of manganese with other $\beta$-stabilizing elements used in $\mathrm{Zr}-\mathrm{Nb}$-based alloys, such as $\mathrm{Mo}$ and $\mathrm{Cu}$, it is noted that $\mathrm{Mn}$ has the solid solution hardening effect, such as $\mathrm{Mo}^{21}$, and enables the formation of fine precipitates of $\beta-\mathrm{Nb}$, such as $\mathrm{Cu}^{23}$, which favors the increase of the corrosion resistance and allows the adjustment among resistance, ductility and manufacturing feasibility. In addition, the increase of the manganese content also promoted higher conformability, which is one of the limitations of the addition of molybdenum ${ }^{21}$. The formation of short and partially aligned hydrides, as well as increased hydrogen solubility and the results of the tensile tests, indicated that manganese may act as a beneficial alloying element for the control of hydrogen embrittlement.

\section{Conclusion}

The present study suggests that manganese can be considered a promising alloying element in zirconium alloys. The results of the computational simulation allowed to understand the effect of the addition of manganese on the zirconium phase transformation and to select the promising compositions. Manganese increased the conformability, improved the strength-ductility ratio due to the solid solution hardening and promoted the formation of $\beta-\mathrm{Nb}$ precipitates, which are responsible for improving the corrosion resistance. With respect to the interaction with hydrogen, the TDS results indicate that the addition of manganese in the studied compositions had no significant influence on the diffusion coefficient; however, it promoted an increase in hydrogen solubility. The addition of manganese at higher contents than $0.2 \mathrm{wt} \%$ resulted in the formation of shorter and partially aligned hydrides, reducing the effects of hydrogen embrittlement, as observed through the reduction of ductility observed in the tensile tests.

\section{Acknowledgments}

The authors acknowledge the Military Institute of Engineering for the TEM images and the financial support of CNPq, CAPES and FAPERJ.

\section{References}

1. Banerjee S, Mukhopadhyay P. Phase transformations - examples from titanium and zirconium alloys. Amsterdam: Elsevier Science; 2007. v. 12.

2. Tian H, Wang X, Gong W, Zhou J, Zhang H. Recrystallization behavior of cold-rolled $\mathrm{Zr}-1 \mathrm{Nb}$ alloy. Journal of Nuclear Materials. 2015;456:321-8.

3. Neogy S, Srivastava D, Tewari R, Singh RN, Dey GK, Banerjee S. Microstructural study of hydride formation in $\mathrm{Zr}-1 \mathrm{Nb}$ alloy. Journal of Nuclear Materials. 2003;322(23):195-203.

4. Yilmazbayhan A, Motta AT, Comstock RJ, Sabol GP, Lai B, Cai Z. Structure of zirconium alloy oxides formed in pure water studied with synchrotron radiation and optical microscopy: relation to corrosion rate. Journal of Nuclear Materials. 2004;324(1):6-22.

5. Shi R, Luo AA. Applications of CALPHAD modeling and databases in advanced lightweight metallic materials. Calphad. 2018;62:1-17.

6. Ribeiro RM, Woyames CB, Almeida LH, Santos DS. Effect of microstructure and addition of alloying elements on hydriding kinetics of Zr-Nb-based alloys. International Journal of Hydrogen Energy. 2015;40(47):17118-27.

7. Conić D, Gradišek A, Radaković J, Iordoc M, Mirković M, Čebela $\mathrm{M}$, et al. Influence of $\mathrm{Ta}$ and $\mathrm{Nb}$ on the hydrogen absorption kinetics in Zr-based alloys. International Journal of Hydrogen Energy. 2015;40(16):5677-82.

8. Gouda MK, Nakamura K, Gepreel MAH. Effect of Mn-content on the deformation behavior of binary Ti-Mn alloys effect of $\mathrm{Mn}$-content on the deformation behavior of binary Ti-Mn alloys. Key Engineering Materials. 2016;705:214-218.

9. Kirchheim R. Bulk diffusion-controlled thermal desorption spectroscopy with examples for hydrogen in iron. Metallurgical and Materials Transactions: A. 2016;47(2):672-96.

10. American Society for Testing and Materials (ASTM). E8/ E8M-15a-Standard test methods for tension testing of metallic materials. West Conshohocken, PA: ASTM International; 2015 .

11. Oliveira LM, Silva RV, Santos DS, Ribeiro RM. Hydrogen kinetics and hydride formation effect on $\mathrm{Zr}-1 \mathrm{Nb}$ and $\mathrm{Zr}-1 \mathrm{Nb}-$ $1 \mathrm{Sn}-0.1 \mathrm{Fe}$ alloys for nuclear application. Materials Research. 2018;20(Suppl 2):786-91.

12. Akben MG, Weiss I, Jonas JJ. Dynamic precipitation and solute hardening in a $\mathrm{V}$ microalloyed steel and two $\mathrm{Nb}$ steels containing high levels of Mn. Acta Metallurgica. 1981;29(1):111-21.

13. Vazquez C, Fortis AM, Bozzano PB. Comparison of mechanical properties of $\mathrm{Zr}-1 \% \mathrm{Nb}$ and $\mathrm{Zr}-2.5 \% \mathrm{Nb}$ alloys. Procedia Materials Science. 2015;8:478-485.

14. Turnbull A, Hutchings RB, Ferriss DH. Modelling of thermal desorption of hydrogen from metals. Materials Science and Engineering: A. 1997;238(2):317-28. 
15. Silva KRF, Santos DS, Ribeiro AF, Almeida LH. Hydrogen diffusivity and hydride formation in rich-zirconium alloys used in nuclear reactors. Defect and Diffusion Forum. 2010;297301:722-727.

16. Singh RN, Mukherjee S, Gupta A, Banerjee S. Terminal solid solubility of hydrogen in Zr-alloy pressure tube materials. Journal of Alloys and Compounds. 2005;389(12):102-12.

17. Shrivastava KC, Kulkarni AS, Ramanjaneyulu PS, Sunil S, Saxena MK, Singh RN, et al. Determination of diffusion coefficients of hydrogen and deuterium in $\mathrm{Zr}-2.5 \% \mathrm{Nb}$ pressure tube material using hot vacuum extraction-quadrupole mass spectrometry. Journal of Nuclear Materials. 2015;461:151-6.

18. Marchi CS, Somerday BP, Robinson SL. Permeability, solubility and diffusivity of hydrogen isotopes in stainless steels at high gas pressures. International Journal of Hydrogen Energy . 2007;32(1):100-16.
19. McRae GA, Coleman CE, Nordin HM, Leitch BW, Hanlon SM. Diffusivity of hydrogen isotopes in the alpha phase of zirconium alloys interpreted with the Einstein flux equation. Journal of Nuclear Materials. 2018;510:337-47.

20. Laursen T, Leger M, Whitton JL. Nuclear reaction analysis of deuterium diffusion in $\mathrm{Zr}-2.5 \mathrm{wt} \% \mathrm{Nb}$ pressure tube material. Journal of Nuclear Materials. 1988;158:49-56.

21. Chun YB, Hwang SK, Kim MH, Kwun SI, Kim YS. Effect of Mo on recrystallization characteristics of $\mathrm{Zr}-\mathrm{Nb}-(\mathrm{Sn})-$ Mo experimental alloys. Journal of Nuclear Materials. 1999;265(1-2):28-37.

22. Yang HL, Matsukawa Y, Kano S, Duan ZG, Murakami K, Abe $\mathrm{H}$. Investigation on microstructural evolution and hardening mechanism in dilute $\mathrm{ZrNb}$ binary alloys. Journal of Nuclear Materials. 2016;481:117-24.

23. Park JY, Choi BK, Jeong YH, Jung YH. Corrosion behavior of $\mathrm{Zr}$ alloys with a high $\mathrm{Nb}$ content. Journal of Nuclear Materials. 2005;340(2):237-46. 